\title{
Atria: A comprehensive evaluation with echocardiography
}

\author{
Oben Baysan, Ezgi Polat Ocakl1, Tugba Kayhan Altuner, Sinan Altan Kocaman \\ Guven Hospital, Cardiology Department, Ankara, Turkey
}

\begin{abstract}
Left and right atria have gained interest from scientific community. Two or three- dimensional echocardiographic methods have been implemented for better understanding of atrial functions in both healthy persons and patients with various diseases. Atrial volume could be calculated from 2D or 3D images. Volumetric data and derived parameters could be used for determining atrial phasic functions. Nowadays, atrial deformation imaging with 2D-TDI, 2D-speckle tracking imaging or with recently introduced 3D speckle tracking is possible. All those methods have some advantages and disadvantages, which define their clinical value in the future.
\end{abstract}

Key Words: left atrium, right atrium, functional evaluation, echocardiography

(Heart Vessels and Transplantation 2017; 1: doi: 10.24969/2017.8)

\section{Introduction}

Both atria are not mere passive chambers lying between their venous openings and respective ventricles. They are interdependently connected to the ventricles for ensuring best cardiac performance. Phasic changes in the atria provide optimal support for left or right ventricular filling. In addition to their mechanical role, the atria release atrial natriuretic peptide in response to stretching. It has potent diuretic, natriuretic and vasorelaxant effects (1).

During ventricular systole, each atrium has reservoir function when both atrioventricular (AV) valves are in closed position. They receive venous flow from the pulmonary veins. Atrial filling by pulmonary vein flow is affected by ventricular contraction, the descent of ventricular base, systemic and pulmonary venous systolic pressure, and atrial properties (ie, relaxation and chamber stiffness). Conduit function of atria begins with early diastole and blood passively flows from atrium to ventricle. Ventricular relaxation, compliance and stiffness as well as ventricular early diastolic pressures are major determinants of conduit function. Late diastolic atrial contractility pumps remaining blood (20$30 \%$ of cardiac stroke volume) actively into the ventricles. The atrial pressure-volume relationship consists of two loops: the A loop representing atrial pump function and the $\mathrm{V}$ loop representing atrial reservoir function (Fig. 1). Factors affecting each phase are shown in Table 1.

Atrial reservoir and booster functions increase with exercise, whereas conduit function is not (2). Enhancement of reservoir function supports ventricular filling by creating higher AV pressure gradient favoring diastolic flow, and also, by increasing atrial pump through an increase in its preload.

Any pressure and/or volume loading conditions such as atrial fibrillation (AF), ischemic heart disease, heart failure, valvular disease, hypertension and diabetes lead to atrial remodeling. Atrial remodeling is caused by electrical, mechanical, and metabolic stressors in a time-dependent way (3). It can be structural, functional, and electrical (4). Longer duration of stressors (> 5 weeks) may cause irreversible atrial damage (apoptosis and fibrosis) (3). While structural remodeling is manifested by atrial dilatation, functional remodeling results in decreased function with or without a change in atrial size. Atrial arrhythmias, especially AF, are the hallmarks of electrical remodeling (Fig. 2) (5). In this review, our aim is to provide better understanding of left and right atrial structural and functional evaluation by focusing on echocardiography. 


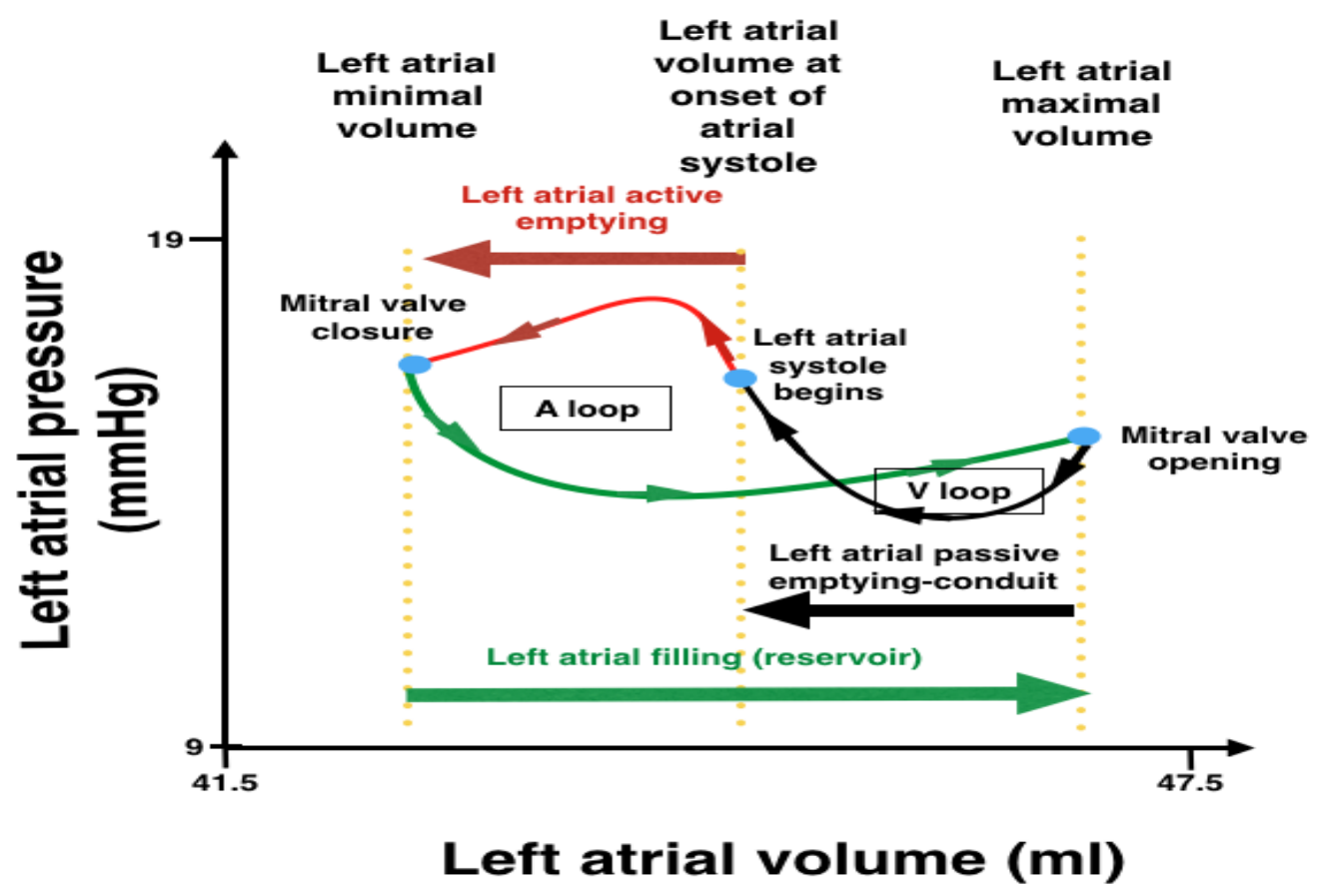

Figure 1. Left atrial pressure to volume loop curves

\section{Left atrium}

\section{Anatomy}

Left atrium (LA) is a posteriorly localized cardiac chamber. Right atrial (RA) localization is anterior and inferior to left atrium (6). Major anatomic parts of left atrium are:

-Left atrial appendage (LAA) is smaller compared to right atrial appendage and shows various forms such as cauliflower, windsock, cactus and chicken wing (7). The shape of LAA has direct effect on embolic risk in patients with AF (8).

-Interatrial septal component is especially related to aorta and transverse pericardial sac at its anterior part. Fossa ovalis as a true anatomic septum is another important structure in this part of left atrium.

-Pulmonary veins are directly opened to venous portion. Left pulmonary veins are superiorly localized compared to right pulmonary veins.

-The vestibule is an outlet portion of left atrium surrounding mitral valve orifice. Coronary sinus is in close contact with the posterior vestibular wall (9).

\begin{tabular}{|l|l|}
\hline \multicolumn{2}{|l|}{ Table 1. Factors affecting atrial functions } \\
\hline Atrial function & Factors affecting the function \\
\hline Reservoir & $\begin{array}{l}\text { Atrial compliance during } \\
\text { ventricular systole } \\
\text { Atrial contractility and } \\
\text { relaxation } \\
\\
\text { Descent of left ventricular base } \\
\text { Ventricular end-systolic volume }\end{array}$ \\
\hline Conduit & $\begin{array}{l}\text { Atrial compliance } \\
\text { Ventricular compliance }\end{array}$ \\
& Ventricular relaxation \\
\hline Booster Pump & $\begin{array}{l}\text { Atrial contractility } \\
\text { Atrial pre-load (venous return) } \\
\text { Atrial after-load (ventricular } \\
\text { end-diastolic pressure) } \\
\text { Ventricular systolic reserve }\end{array}$ \\
\hline
\end{tabular}

\section{Left atrial size and phasic function}

Increased left atrial size is a marker reflecting left ventricular diastolic dysfunction (4). That is an early step in a cascade of events ending with left atrial failure (Fig. 2) (5). Enlargement of left atrium is a predictor of both all-cause mortality $(10,11)$ and future cardiovascular events such as AF (12). 


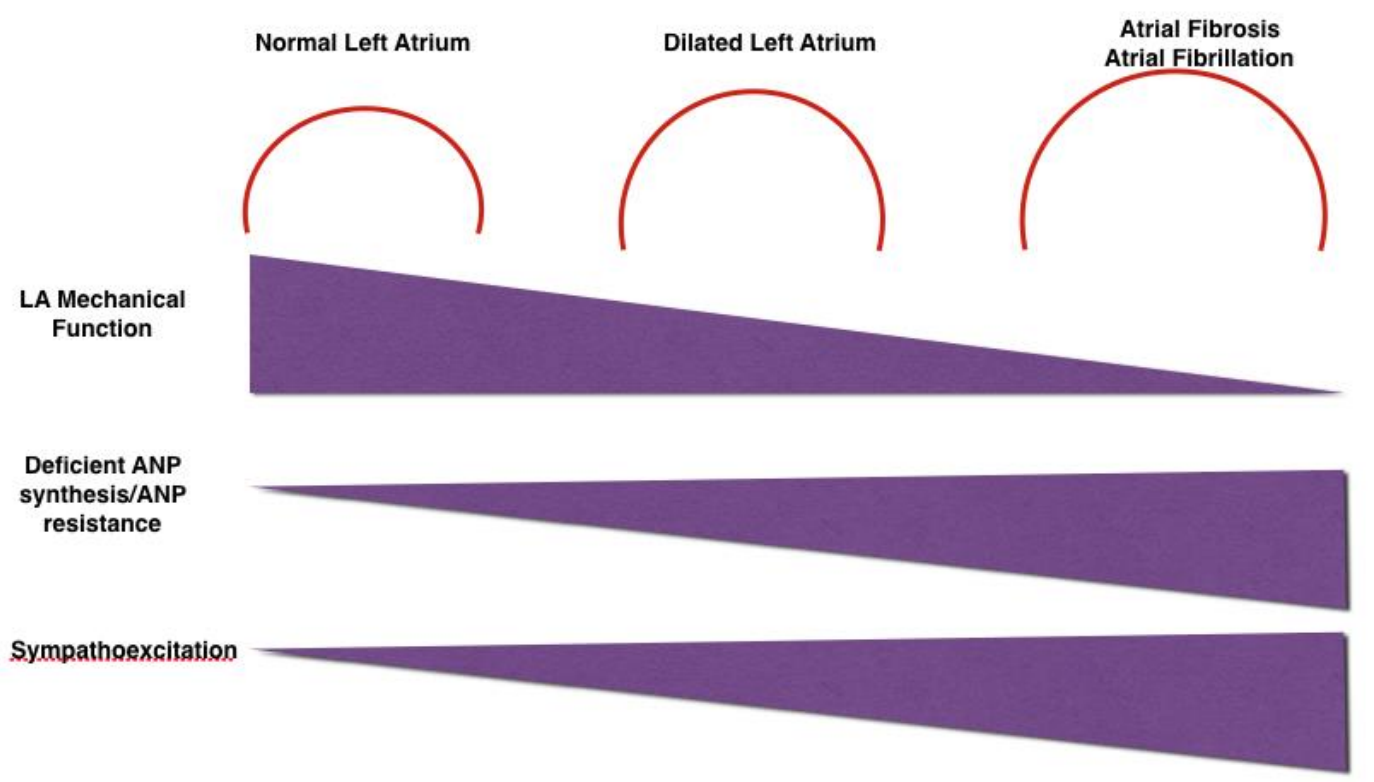

Figure 2. Changes in left atrial structural, mechanical and electrical properties with left atrial dilatation (Modified from ref. 5)

It is also a marker for worse prognosis in patients with heart failure (preserved or reduced ejection fraction) (13), valvular heart disease (14) and diabetes (15).

Echocardiography, cardiac computed tomography (cCT) and cardiac magnetic resonance (cMR) could be used for assessment of atrial size and function. Echocardiography is by far the most commonly used imaging technique because of its availability, versatility, safety and cost. It is associated with high temporal and spatial resolution. Transthoracic echocardiography (TTE) should be used for determining atrial size because transesophageal echocardiographic (TEE) views cannot show entire left atrium.

\section{a) LA diameter}

TTE M-mode or two-dimensional (2D) based parasternal long-axis antero-posterior (AP) diameter at end-systole has traditionally been used linear dimension reflecting left atrial size. An increased AP diameter is a risk factor for incident $\mathrm{AF}$ (16, 17), stroke, and death (18). An AP diameter $\geq 55 \mathrm{~mm}$ also has prognostic value in patients with mitral regurgitation (19).

Unfortunately, LA is a three-dimensional structure, and hence, one-dimensional measurement of AP diameter could not reflect true left atrial size. Indeed, AP diameter measurement underestimates true left atrial volume (LAV) (20) Recent guideline about chamber quantification recommended that AP linear dimension should not be used as the sole measure of LA size (21).

\section{b) LA area}

Left atrial area can be calculated from apical 4and 2-chamber views but again superseded by left atrial volume measurement. Reference values for AP diameter and LA area are shown in Table 2 (22).

\begin{tabular}{|c|c|c|}
\hline Parameters & Mean (SD) & 2SD range \\
\hline $\begin{array}{l}\text { LA diameter-PLAX } \\
(\mathrm{mm})\end{array}$ & $33.6(4.3)$ & $26.7-41$ \\
\hline $\begin{array}{l}\text { LA area }\left(\mathrm{cm}^{2}\right) \\
\text { Ap4Ch }\end{array}$ & $16.5(3.2)$ & $11.5-21.9$ \\
\hline $\begin{array}{l}\text { LA area }\left(\mathrm{cm}^{2}\right) \\
\text { Ap2Ch }\end{array}$ & $17.5(3.1)$ & $12.7-23.1$ \\
\hline
\end{tabular}


c) LA Functional Assessment By Pulsed Wave Doppler

Both pulse-wave (PW) mitral (E and A waves) and pulmonary vein waves (S, D and A waves) are used for evaluation of left ventricular filling pressures. Those waves are also show valuable information about LA phasic functions (Table 35) (23-25).

Left atrial ejection force (26) and kinetic energy (LAKE) (27) are calculated from PW data and reflect atrial function but their use is not recommended at this time, which is probably related to lack of robust data and time-consuming calculation from multiple parameters (21).

\section{d) LA volume}

Ellipsoid model, disk summation and area- length methods can be used for LAV measurement (28). All three methods require good image quality with clear LA border, exclusion of LAA and pulmonary vein orifices from the measurement, and end-systolic timing.

Volumes by the ellipsoid method were consistently smaller than other two methods. The mean LA volume indexed to body surface area was $27(12) \mathrm{ml} / \mathrm{m} 2$ for ellipsoid method, 37(16) $\mathrm{ml} / \mathrm{m} 2$ for area-length method, and 34(14) $\mathrm{ml} / \mathrm{m} 2$ for Simpson's method (29). Relative inaccuracy of ellipsoid method has led to Simpson's disk summation method as preferred volume measurement tool (21).

\begin{tabular}{|l|l|l|l|}
\hline Table 3. PW Doppler parameters and left atrial phasic functions (23) \\
\hline LA function & Transmitral flow & Pulmonary venous flow & Composite indexes \\
\hline Reservoir & & S velocity and VTI & \\
\hline Conduit & E velocity, E/A ratio & D velocity and VTI & \\
\hline Booster function & A velocity, E/A ratio & PVa & Ejection force, LAKE \\
\hline $\begin{array}{l}\text { A - atrial contractility filling phase, E- early diastolic filling, LA - left atrium, LAKE-LA kinetic energy, PW - pulse-wave, } \\
\text { PVa - pulmonary vein A wave, VTI - velocity time integral }\end{array}$ \\
\hline
\end{tabular}

\begin{tabular}{|l|l|l|l|}
\hline \multicolumn{4}{|c|}{ Table 4. Normal values for mitral inflow normal PW Doppler parameters (24) } \\
\hline \multirow{2}{*}{ Parameters } & \multicolumn{3}{|c|}{ Age groups } \\
\cline { 2 - 4 } & $20-40$ & $40-60$ & 60 \\
\hline E velocity $(\mathrm{cm} / \mathrm{sec})$ & $0.82(0.16)$ & $0.75(0.17)$ & $0.70(0.16)$ \\
\hline A velocity $(\mathrm{cm} / \mathrm{sec})$ & $0.50(0.13)$ & $0.62(0.15)$ & $0.74(0.16)$ \\
\hline E/A ratio & $1.71(0.50)$ & $1.24(0.19)$ & $0.98(0.29)$ \\
\hline $\begin{array}{l}\text { Data are presented as Mean (SD) } \\
\text { A - atrial contractility filling phase, E- early diastolic filling, PW - pulse wave }\end{array}$ \\
\hline
\end{tabular}

Table 5. Reference values for PW Doppler pulmonary vein flow parameters (25)

\begin{tabular}{|l|l|l|l|l|}
\hline \multirow{2}{*}{} & \multicolumn{5}{l|}{ Age groups (years) } \\
\cline { 2 - 5 } & $16-20$ & $21-40$ & $41-60$ & $>60$ \\
\hline PV S/D ratio & $0.82(0.18)$ & $0.98(0.32)$ & $1.21(0.2)$ & $1.39(0.47)$ \\
\hline PV Ar (cm/sec) & $16(10)$ & $21(8)$ & $23(3)$ & $25(9)$ \\
\hline PV Ar duration & $66(39)$ & $96(33)$ & $112(15)$ & $112(15)$ \\
\hline $\begin{array}{l}\text { Data are presented as Mean (SD) } \\
\text { Ar - reversal flow during atrial contraction, PW - pulse wave PV - pulmonary vein, S/D - systolic/diastolic }\end{array}$ \\
\hline
\end{tabular}




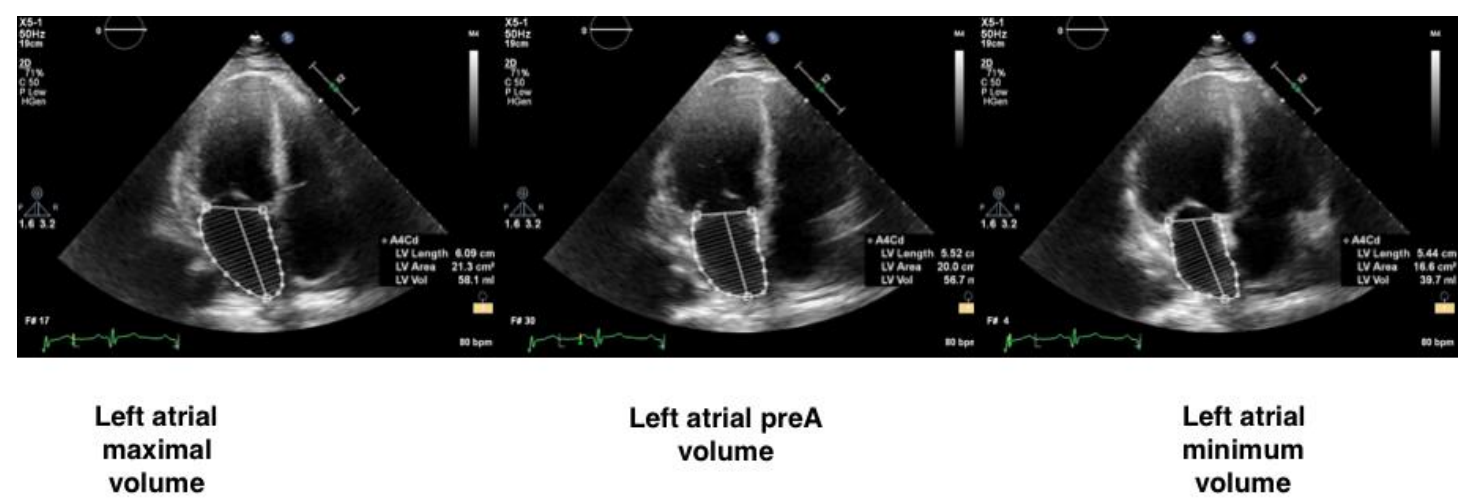

Figure 3. 2D- echocardiographic left atrial volumes measurement: apical 4- chamber view

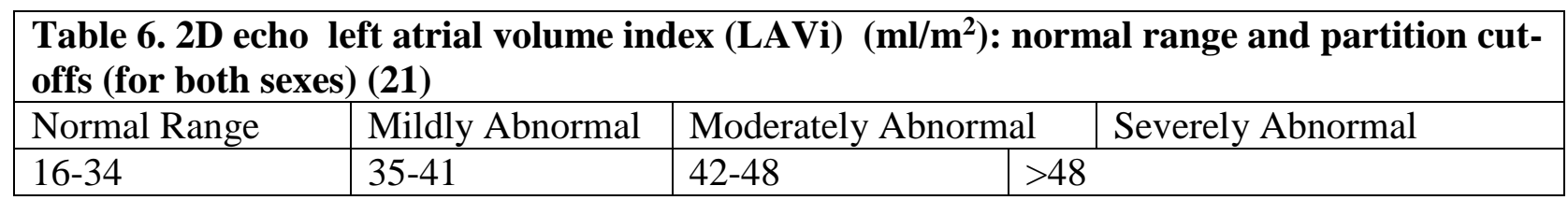

Area-length method can be used as an alternative. Apical four- and two- chamber views are needed for better volumetric calculation but single-plane measurements could be used in case of insufficient biplane planimetry. Measured LA volumes are maximal LA volume (end-systolic volume) just before the opening of the mitral valve at end-systole, (ECG: at the end of the T wave), the minimal LA volume at end-diastole when the mitral valve is closed (ECG: at the beginning of QRS) and just before atrial systole (ECG: at the beginning of $\mathrm{P}$ wave) (Fig. 3).

Left atrial volume is directly affected by gender. Indexing according to body size area overcomes this restriction and should always be used when reporting LAV. The upper normal limit for 2D echocardiographic LAV index (LAVi) is 34 $\mathrm{mL} / \mathrm{m}^{2}$ for both genders (Table 6) (21). LAVi is an independent predictor of adverse cardiovascular events including stroke, heart failure, myocardial infarction and AF (30).

Apart from LAVi, minimal LAV measured at the end-diastole has capacity to predict an increased pulmonary wedge pressure if it is more than $40 \mathrm{ml}$ (31).

Geometric assumptions and difficulty in obtaining correct LA alignment restrict accuracy of 2D TTE volumetric measurements. LA diameter, area or volume values are relatively crude evaluation for an active heart chamber. Functional parameters may be better suited for more in-depth analysis of atria and may provide a framework for examining atria in both healthy and disease conditions. Indeed, LA phasic changes occur earlier in disease process and could provide early diagnosis compared to LA enlargement (32). Volume-based calculation or tissue Doppler/deformation imaging could be used for this purpose (Table 7-8).

Increasing age comes with decreasing conduit function but pronounced active pump function of LA (35). LA reservoir function did not vary with age or sex (35). In early stage of left ventricular dysfunction (mild degree of increased left ventricular filling pressures) LA reservoir and conduit functions decrease with an increase in booster pump function. Advancement of left ventricular diastolic dysfunction causes impairment in all phases of LA function $(36,37)$.

LA emptying fraction (LAEF) has been shown to be an independent predictor of mortality and incident $\operatorname{AF}(38,39)$. Patients with both LAEF < $49 \%$ and $\mathrm{LAVi}>38 \mathrm{ml} / \mathrm{m}^{2}$ are at the highest risk of events (39). 


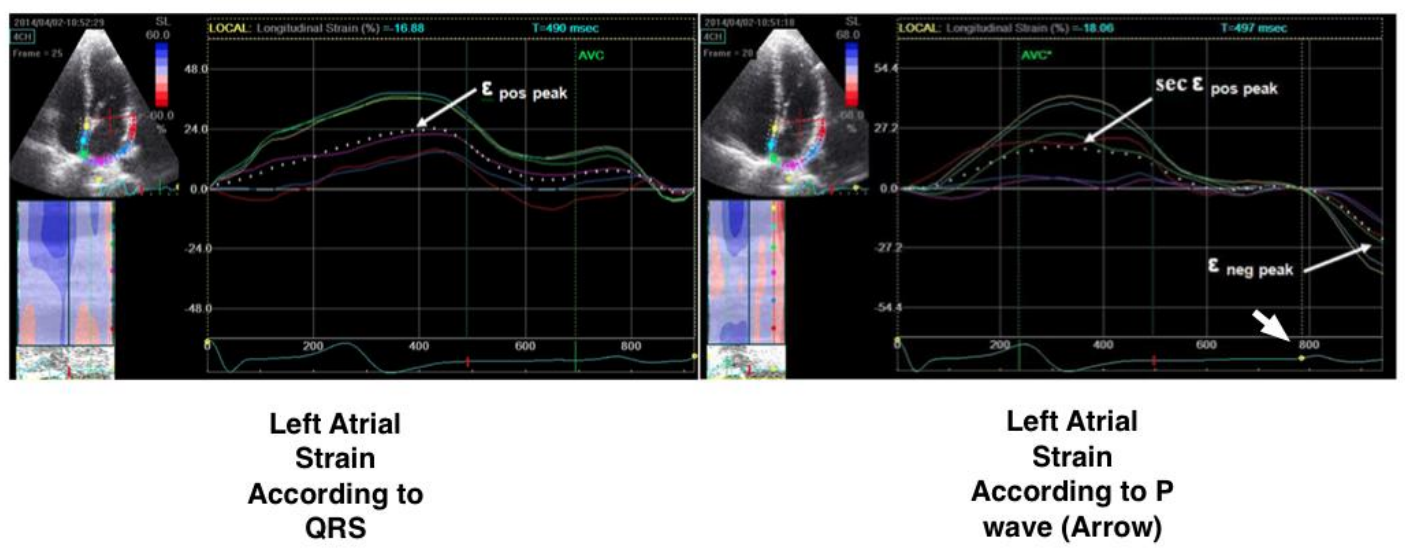

Figure 4. 2D -echocardiographic left atrial strain measurement

(Reproduced from ref 44. in frame of open access creative common

license by 4. (C) licensee BioMed Central Ltd. 2014)

\section{Table 7. Volume-derived indexes of left atrial functional assessment $(23,33)$ \\ LA global function \\ Left atrial functional index $(\mathrm{LAFI})=(\mathrm{LAEF} \times$ left ventricular outflow tract-velocity time integral [LVOT-VTI])/LAVimin}

\section{LA reservoir function:}

LA total emptying volume: $\mathrm{LAV}_{\max }-\mathrm{LAV}_{\min }$

LA emptying fraction (LAEF) : $\mathrm{LAV}_{\max }-\mathrm{LAV}_{\min } / \mathrm{LAV}_{\max }$ [normal values:70(9)]

\section{LA conduit function}

LA passive emptying volume: $\mathrm{LAV}_{\max }-\mathrm{LAV}_{\text {preA }}$

LA passive emptying fraction (Passive EF): $\mathrm{LAV}_{\max }-\mathrm{LAV}_{\text {preA }} / \mathrm{LAV}_{\max } \quad$ [normal values:44(12)]

Conduit Volume $=$ Stroke volume - Total emptying volume

\section{LA booster pump function}

LA active emptying volume: $L A V_{\text {preA }}-\mathrm{LAV}_{\min }$

$\mathrm{LA}$ active emptying fraction (Active $\mathrm{EF}$ ): $\mathrm{LAV}_{\mathrm{preA}}-\mathrm{LAV}_{\min /} \mathrm{LAV}_{\mathrm{preA}}[$ normal values:47(12)]

A - atrial contractility, EF - emptying fraction LA - left atrium, LAV - left atrial volume

\begin{tabular}{|c|c|c|c|}
\hline LA function & Tissue Velocity & Strain $\varepsilon$ & Strain rate \\
\hline Reservoir & $\mathrm{S}^{\prime}$ & $\varepsilon s$ (total) & SR-S' \\
\hline Conduit & $\mathrm{E}^{\prime}$ & $\varepsilon e$, epos & SR-E' \\
\hline Booster pump & $\mathrm{A}^{\prime}$ & عa , sneg & SR-A' \\
\hline
\end{tabular}

LAFI is dependent on LA conduit function and independent of cardiac rhythm disturbances (40). LAFI $>16.57$ is a strong predictor of long-term survival in patients with heart failure with reduced ejection fraction (33). e) LA tissue Doppler velocities (TDI)

TDI records high amplitude low frequency atrial wall velocities. Examination should be performed at end-expiration with sample volume on the atrial side of the mitral annulus at the basal inter-atrial septum from the apical four-chamber view. 
Peak ventricular systolic velocity $\left(\mathrm{S}^{\prime}\right)$, peak early diastolic velocity $\left(\mathrm{E}^{\prime}\right)$ and peak atrial contractility $\left(\mathrm{A}^{\prime}\right)$ could be recorded. E'velocity decreases with aging but $\mathrm{A}^{\prime}$ shows no change. $\mathrm{A}^{\prime}$ velocity has direct relationship with atrial function $(41,42)$. In patients with various cardiac diseases, $\mathrm{A}^{\prime}$ wave velocity lower than $4 \mathrm{~cm} / \mathrm{s}$ points to a higher cardiac mortality (43).

Tissue Doppler velocities (Table 9) have important restrictions: measurement error due to angle dependency, and the effects of cardiac motion and tethering.

\section{Table 9. Normal values for tissue Doppler} based parameters (26)

\begin{tabular}{|c|c|c|c|}
\hline & \multicolumn{3}{|c|}{ Age groups } \\
\hline & $20-40$ & $40-60$ & 60 \\
\hline & $\begin{array}{l}\text { Mean } \\
\text { (SD) }\end{array}$ & $\begin{array}{l}\text { Mean } \\
\text { (SD) }\end{array}$ & $\begin{array}{l}\text { Mean } \\
\text { (SD) }\end{array}$ \\
\hline $\begin{array}{l}\text { Septal } \\
E^{\prime}(\mathrm{cm} / \mathrm{sec})\end{array}$ & $12.1(2.5)$ & $9.8(2.6)$ & $7.6(2.3)$ \\
\hline $\begin{array}{l}\text { Septal } \\
\mathrm{A}^{\prime}(\mathrm{cm} / \mathrm{sec})\end{array}$ & $8.5(1.7)$ & $9.8(2.0)$ & $10.5(1.7)$ \\
\hline $\begin{array}{l}\text { Lateral } \\
\mathrm{E}^{\prime}(\mathrm{cm} / \mathrm{sec})\end{array}$ & $16.4(3.4)$ & $12.5(3.0)$ & $9.6(2.8)$ \\
\hline $\begin{array}{l}\text { Lateral } \\
\mathrm{A}^{\prime}(\mathrm{cm} / \mathrm{sec})\end{array}$ & $8.2(2.2)$ & $9.4(2.6)$ & $10.6(2.9)$ \\
\hline
\end{tabular}

\section{f) LA 2D Deformation Analysis}

Myocardial deformation imaging encompasses TDI or 2D-based (speckle tracking) methods. TDI, as previously mentioned, has angle dependence and signal to noise ratio sometimes could be problematic. Therefore, 2D methods with speckle tracking (2D STE) has gained acceptance in many echocardiography laboratories.

2D STE is an angle independent imaging method but needs good image quality and relatively high frame rate (50-70 frame/sec) for accurate tracking. 2D STE is used for determination of strain and strain rate (SR) values from 6-12 segments (apical 4-3-2- chamber views)

Two reference points on ECG could be selected for left atrial deformation imaging: onset of QRS complex or $\mathrm{P}$ wave. If the $\mathrm{QRS}$ complex is marked as reference point, peak positive longitudinal atrial strain corresponds to reservoir function. Early and late diastolic strain waves (ce and $\varepsilon a$, respectively) point to atrial conduit and booster pump functions. In contrast, if $\mathrm{P}$ wave is selected, first negative peak $\varepsilon$ ( $\varepsilon$ neg) represents the atrial booster pump function, positive peak $\varepsilon$ (عpos) corresponds to conduit function, and their sum (ctotal) represents reservoir function (Fig. 4) (44).

Lower peak longitudinal strain values is associated with possibility of having permanent AF (45), worse prognosis after acute myocardial infarction (46), and higher grade mitral regurgitation (47).

An interesting research area for deformation imaging is the determination of atrial fibrosis. This task could be accomplished with cMR (48) but echocardiographic methods can be used for obtaining data indirectly reflecting the presence of fibrosis. Peak positive longitudinal strain (Table 10) (50) reflects left atrial stretching capacity during reservoir phase, and hence, directly related to atrial compliance which adversely affected by fibrosis (49). There is a negative correlation between peak atrial longitudinal strain and degree of atrial fibrosis in patients with AF (51) and mitral regurgitation (52).

\begin{tabular}{|l|l|l|l|}
\hline \multicolumn{4}{|c|}{$\begin{array}{l}\text { Table 10. Grading of 2D speckle tracking } \\
\text { (STE) peak atrial longitudinal strain (50) }\end{array}$} \\
\hline Normal & $\begin{array}{l}\text { Mildly } \\
\text { Abnormal }\end{array}$ & $\begin{array}{l}\text { Moderately } \\
\text { Abnormal }\end{array}$ & $\begin{array}{l}\text { Severely } \\
\text { Abnormal }\end{array}$ \\
\hline$>40 \%$ & $30-<40 \%$ & $23-<30 \%$ & $<23 \%$ \\
\hline
\end{tabular}

Left atrial deformation analysis brings some difficulties compared to left ventricular speckle tracking. Left atrium is positioned at far field of echocardiographic window, and hence, image quality is relatively poor with low signal-to-noise ratio. Motion of some speckles out of image plane causes error in strain and strain rate calculations. Thin walled left atrium also could lead to more variability on different software vendors. Left atrium specific software packages with clear reference and time points are needed. 2D STE based left atrial functional imaging may have a future if above-mentioned restrictions to be solved. 
g) LA Volume - Strain Analysis Based On Three Dimensional Data

Three-dimensional (3D) echocardiographic left atrial volume calculation shows better correlation with cCT and magnetic resonance compared to $2 \mathrm{D}$ volumes $(53,54)$. 3D volume analysis does not require any geometric assumption. Regrettably, it is dependent on image quality and has lower temporal resolution. Pyramidal 3D datasets including LA volumes can be obtained with wideangle mode from apical 4-chamber view. Offline analysis with a dedicated software is required for final analysis which takes 4-5 min for each atrium
(55). Three LA volumes as in 2D volumetric data could be calculated: LAVmax, LAVmin and LAV pre A (Fig. 5) (56). There is a paucity of data about 3D left atrial volume in both healthy subjects and patients with various diseases (Table 11) (55). From 3D speckle data several global or segmental unidirectional strain parameters could be calculated including radial (RS), longitudinal (LS) and circumferential strains (CS). (57). More complex multidirectional variables such as area strain (AS) and 3D strains could also be determined (57).
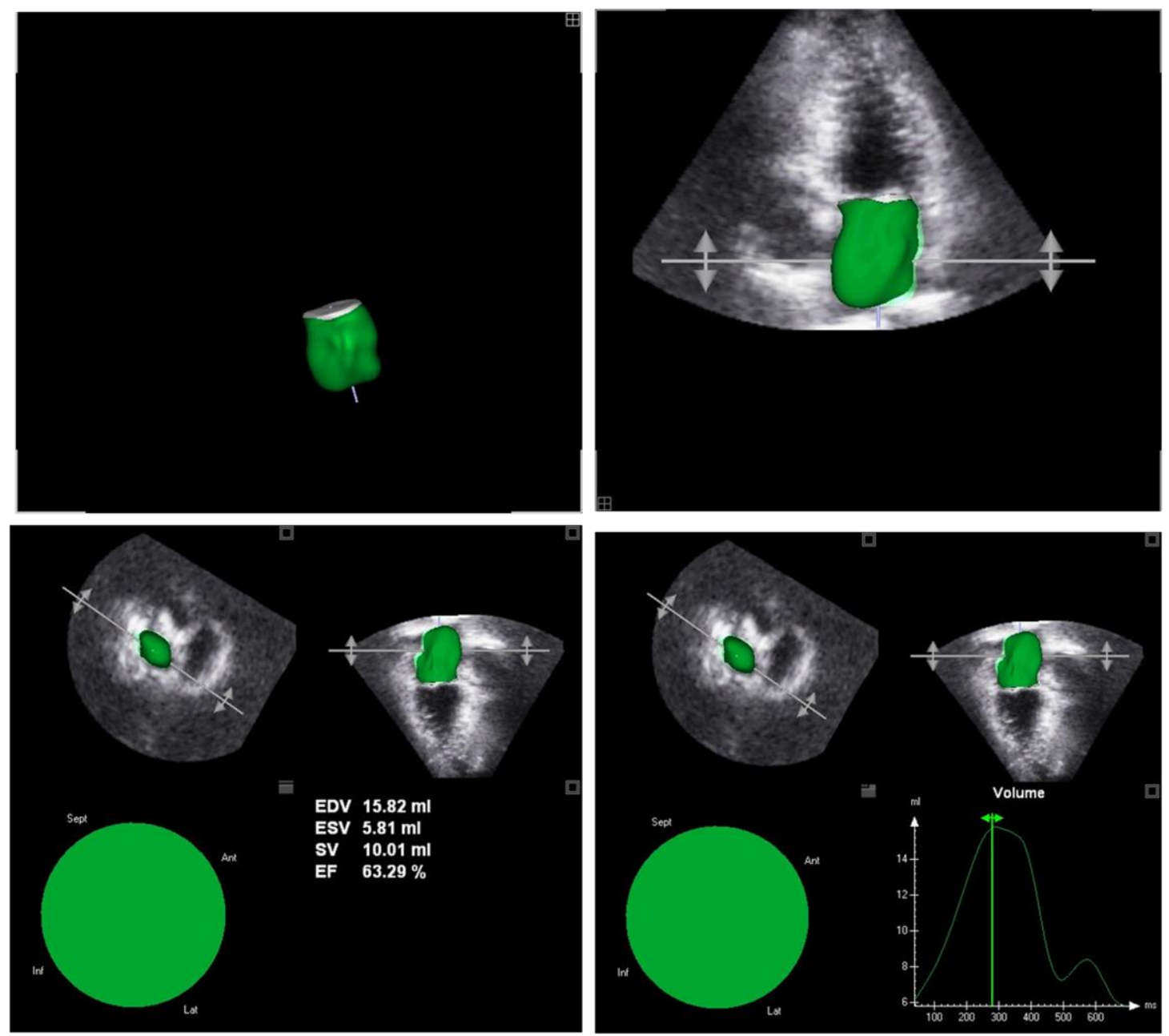

Figure 5. 3D-echocardiographic left atrial volume measurement

(Reproduced from reference 56 in frame of open access creative common license by 2. (C) licensee BioMed Central Ltd. 2012) 


\begin{tabular}{|c|c|c|c|}
\hline RT3DE & Males $(n=75)$ & Females $(\mathrm{n}=84)$ & Total study group $(n=159)$ \\
\hline LAVi $\max \left(\mathrm{ml} / \mathrm{m}^{2}\right)$ & $15-42$ & $15-39$ & $15-41$ \\
\hline LAVi $\min \left(\mathrm{ml} / \mathrm{m}^{2}\right)$ & $6-20$ & $5-18$ & $5-19$ \\
\hline $\operatorname{LAEF}(\%)$ & $46-77$ & $44-80$ & $45-79$ \\
\hline
\end{tabular}

\begin{tabular}{|c|c|c|}
\hline & Women & Men \\
\hline Indexed RA minor axis dimension $\left(\mathrm{mm} / \mathrm{m}^{2}\right)$ & $20.2(3.0)$ & $19.8(2.8)$ \\
\hline Indexed RA major axis dimension $\left(\mathrm{mm} / \mathrm{m}^{2}\right)$ & $26.1(3.2)$ & $24.8(2.5)$ \\
\hline Indexed RA area $\left(\mathrm{cm}^{2} / \mathrm{m}^{2}\right)$ & $7.8(1.6)$ & $8.3(1.4)$ \\
\hline 2D RA volume index $\left(\mathrm{ml} / \mathrm{m}^{2}\right)$ (Simpson) & $19.0(1.2)$ & $22.5(6.5)$ \\
\hline
\end{tabular}

\begin{tabular}{|l|l|l|l|}
\hline Table 13. 3D right atrial volumes: normal reference ranges (95\% confidence intervals) (55) \\
\hline RT3DE & Males $(\mathrm{n}=75)$ & Females $(\mathrm{n}=84)$ & Total study group $(\mathrm{n}=159)$ \\
\hline RAVi $\max \left(\mathrm{ml} / \mathrm{m}^{2}\right)$ & $18-50$ & $17-41$ & $18-47$ \\
\hline RAVi $\min \left(\mathrm{ml} / \mathrm{m}^{2}\right)$ & $7-22$ & $5-18$ & $5-20$ \\
\hline RAEF $(\%)$ & $46-74$ & $48-83$ & $46-80$ \\
\hline $\begin{array}{l}\text { 3D - 3- dimensional, RAEF - right atrial emptying fraction, RAVi - right atrial volume index, RT3DE - real time 3 - } \\
\text { dimensional echocardiography }\end{array}$
\end{tabular}

\section{Right atrium}

Right ventricle, once forgotten chamber, has been gained attention from medical community but research about right atrium has been very scarce. Right ventricular filling is provided by right atrium with its reservoir, conduit and booster pump functions. RA reservoir function predominates right ventricular filling under normal conditions with increased ventricular pressures favoring conduit function (58).

In chronic RV pressure overload, the RV diastolic function is impaired but systolic function may be preserved. RA compensated that with enhanced contractility and distensibility (59). A chronic volume overload state such as tricuspid regurgitation significantly reduces the RA reservoir phase mechanics (60).

\section{Anatomy}

Right atrium has major anatomic landmarks as follows:

- Anteriorly located appendage

- Crista terminalis: A muscle bundle passes from vena cava superior to vena cava inferior at right atrial anteromedial wall. Crista terminalis is a boundary between venous portion and appendage.

- Cavotricuspid isthmus: An endocardial region delineated anteriorly by the annular attachment of septal and lateral tricuspid leaflets, posteriorly by the vena cava inferior rim and the Eustachian valve, laterally by the crista terminalis, and medially by the coronary sinus.

- Interatrial septum and foramen ovale 


\section{Right atrial size and phasic function}

Enlarged RA has prognostic importance in pulmonary hypertension, systolic heart failure, Eisenmenger syndrome and pulmonary embolism (61-65). RA size and function could be evaluated by similar 2D-echocardiographic methods as LA. Linear dimensions, volumetric methods and deformation imaging could be selected according to local expertise and availability.

\section{$R A$ linear dimensions, area and volume}

RA volume instead of linear dimensions recommended for RA size evaluation (21). Major and minor axis linear dimensions taken from Apical 4-chamber view are shown in Table 12 (22). RA volumes are affected by gender and are smaller than LA volumes because of monoplane calculation compared to biplane LA volume determination (21).

\section{RA 2D Deformation Analysis}

Apical 4-chamber view should be used for speckle tracking based deformation imaging. Strain and strain rate calculation and derived parameters are same as for LA. If P wave on ECG was taken for reference point, following parameters could be measured: first negative peak $\varepsilon$ ( $\varepsilon$ neg) represents the atrial booster pump function, positive peak $\varepsilon$

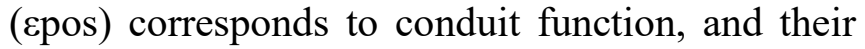
sum (Etotal) represents reservoir function (66). In contrast, peak positive longitudinal atrial strain, early and late diastolic strain waves ( $\varepsilon$ e and $\varepsilon a$, respectively) are recorded according to QRS complex on ECG reference point (67). These correspond to reservoir, conduit, and booster pump functions respectively. There are no standardized cut-off values for right atrial strain but Padeletti et al. reported RA total strain value of 49 (13)\% and RA strain during late diastole $18(6.38) \%$ (67). Reported mean (SD) values for $\mathrm{P}$ wave based analysis were: total RA strain 44 (10)\%, peak positive RA strain 27(9)\% and peak negative strain $-17(4) \%$ (66). A decreased peak
RA systolic strain was independently predictive of clinical outcomes in PAH (68).

\section{$R A$ volume - strain analysis based on three dimensional data}

RA assessment with 3D echocardiography is a feasible and reproducible technique (66). Morenao et al showed that 3D RA volume values were higher than 2D volume values with poor correlation and agreement between two methods (69). Aune et al. (55) provided normal reference values for 3D RA volumes (Table 13) (55).

\section{Future Directions}

Echocardiographic examination of both atria underwent an evolutionary process from simple anteroposterior diameter measurement to sophisticated 3D volume strain analysis. Each step in this long way adds invaluable information to current understanding. 3D analysis holds promise for the future but many obstacles exist such as poor image quality and exclusion of some anatomic structures from the analysis. Right or left atrium specific software capable of feasible, accurate and reproducible analysis certainly required. 2D and 3D volumetric and specklebased deformation imaging data have to be standardized with clear cut-off values. Combining data reflecting structural and functional properties of atrium (ie: volume and strain data) may provide early diagnosis of atrial problems.

That information could be used for effective treatment, or at least, for preventing or delaying disease processes.

Peer-review: External and internal Conflict of interest: None declared Authorship: O.B., E.P.O., T.K.A., S.A.K. equally contributed and fulfilled all authorship criteria.

Acknowledgement and funding: No funding or material support was received for study and preparation of manuscript 


\section{References}

1. De Vito P. Atrial natriuretic peptide: an old hormone or a new cytokine? Peptides. 2014; 58: $108-16$.

2. Stefanadis C, Dernellis J, Toutouzas P. A clinical appraisal of left atrial function. Eur Heart J 2001; 22: 22-36.

3. Casaclang-Verzosa G, Gersh BJ, Tsang TS. Structural and functional remodeling of the left atrium: clinical and therapeutic implications for atrial fibrillation. J Am Coll Cardiol 2008; 51: $1-11$.

4. Thomas L, Abhayaratna WP. Left atrial reverse remodeling: mechanisms, evaluation, and clinical significance. JACC Cardiovasc Imaging. 2017; 10: 65-77.

5. Triposkiadis F, Pieske B, Butler J, Parissis J, Giamouzis G, Skoularigis J, et al. Global left atrial failure in heart failure. EurJ Heart Fail 2016; 18: 1307-20.

6. Ho SY, Cabrera JA, Sanchez-Quintana D. Left atrial anatomy revisited. Circ Arrhythm Electrophysiol 2012; 5: 220-8.

7. Beigel R, Wunderlich NC, Ho SY, Arsanjani R, Siegel RJ. The left atrial appendage: anatomy, function, and noninvasive evaluation. JACC Cardiovasc Imaging 2014; 7: 1251-65.

8. Lupercio F, Carlos Ruiz J, Briceno DF, Romero J, Villablanca PA, Berardi C, et al. Left atrial appendage morphology assessment for risk stratification of embolic stroke in patients with atrial fibrillation: A meta-analysis. Heart Rhythm 2016; 13: 1402-9.

9. Sanchez-Quintana D, Lopez-Minguez JR, Macias Y, Cabrera JA, Saremi F. Left atrial anatomy relevant to catheter ablation. Cardiol Res Pract 2014; 2014: 289720.

10. Chrysohoou C, Pitsavos C, Lazaros G, Skoumas J, Tousoulis D, Stefanadis C. Determinants of all-cause mortality and incidence of cardiovascular disease (2009 to 2013) in older adults: The Ikaria Study of the Blue Zones. Angiology 2016; 67: 541-8.

11. Patel DA, Lavie CJ, Gilliland YE, Shah SB, Dinshaw HK, Milani RV. Prediction of allcause mortality by the left atrial volume index in patients with normal left ventricular filling pressure and preserved ejection fraction. Mayo Clin Proc 2015; 90:1499-505.

12. Tsang TS, Barnes ME, Bailey KR, Leibson CL, Montgomery SC, Takemoto Y, et al. Left atrial volume: important risk marker of incident atrial fibrillation in 1655 older men and women. Mayo Clinic Proc 2001; 76: 467-75.

13. Ramu B, Elwan AM, Coleman CI, Silverman DI, Gluck JA. The association between baseline left atrial volume index and all-cause mortality in patients with heart failure: a metaanalysis. Connecticut Med 2015;79: 469-75.

14. Dalsgaard M, Egstrup K, Wachtell K, Cramariuc D, Kjaergaard J, Gerdts E, et al. Left atrial volume as predictor of valve replacement and cardiovascular events in patients with asymptomatic mild to moderate aortic stenosis. Echocardiography 2013; 30: 1008-14.

15. Kadappu KK, Boyd A, Eshoo S, Haluska B, Yeo AE, Marwick TH, et al. Changes in left atrial volume in diabetes mellitus: more than diastolic dysfunction? Eur Heart J Cardiovasc Imaging. 2012;13: 1016-23.

16. Vaziri SM, Larson MG, Benjamin EJ, Levy D. Echocardiographic predictors of nonrheumatic atrial fibrillation. The Framingham Heart Study. Circulation 1994; 89: 724-30.

17. Flaker GC, Fletcher KA, Rothbart RM, Halperin JL, Hart RG. Clinical and echocardiographic features of intermittent atrial fibrillation that predict recurrent atrial fibrillation. Stroke Prevention in Atrial Fibrillation (SPAF) Investigators. Am J Cardiol 1995; 76: 355-8.

18. Benjamin EJ, D'Agostino RB, Belanger AJ, Wolf PA, Levy D. Left atrial size and the risk of stroke and death. The Framingham Heart Study. Circulation 1995; 92: 835-41.

19. Rusinaru D, Tribouilloy C, Grigioni F, Avierinos JF, Suri RM, Barbieri A, et al. Left atrial size is a potent predictor of mortality in mitral regurgitation due to flail leaflets: results from a large international multicenter study. Circulation Cardiovasc Imag 2011; 4: 473-81.

20. Lester SJ, Ryan EW, Schiller NB, Foster E. Best method in clinical practice and in research studies to determine left atrial size. Am J Cardiol 1999; 84: 829-32.

21. Lang RM, Badano LP, Mor-Avi V, Afilalo J, Armstrong A, Ernande L, et al. 
Recommendations for cardiac chamber quantification by echocardiography in adults: An update from the American Society of Echocardiography and the European Association of Cardiovascular Imaging. Eur Heart $\mathbf{J}$ Cardiovasc Imaging 2015; 16: 233-71.

22. Kou S, Caballero L, Dulgheru R, Voilliot D, De Sousa C, Kacharava G, et al. Echocardiographic reference ranges for normal cardiac chamber size: results from the NORRE study. Eur Heart J Cardiovasc Imaging 2014; 15: 680-90.

23. Lupu S, Mitre A, Dobreanu D. Left atrium function assessment by echocardiography physiological and clinical implications. Med Ultrason 2014; 16: 152-9.

24. Caballero L, Kou S, Dulgheru R, Gonjilashvili N, Athanassopoulos GD, Barone D, et al. Echocardiographic reference ranges for normal cardiac Doppler data: results from the NORRE Study. Eur Heart J Cardiovasc Imaging. 2015; 16:1031-41.

25. Lancellotti P, Cosyns B. The EACVI Echo Handbook. United States of America: Oxford University Press; 2016. 588 p.

26. Manning WJ, Silverman DI, Katz SE, Douglas PS. Atrial ejection force: a noninvasive assessment of atrial systolic function. J Am Coll Cardiol 1993; 22: 221-5.

27. Boudoulas KD, Sparks EA, Rittgers SE, Wooley CF, Boudoulas H. Factors determining left atrial kinetic energy in patients with chronic mitral valve disease. Herz 2003; 28: 437-44.

28. Vizzardi E, D'Aloia A, Rocco E, Lupi L, Rovetta R, Quinzani F, et al. How should we measure left atrium size and function? J Clin Ultrasound 2012; 40: 155-66.

29. Jiamsripong P, Honda T, Reuss CS, Hurst RT, Chaliki HP, Grill DE, et al. Three methods for evaluation of left atrial volume. Eur J Echocardiogr 2008; 9: 351-5.

30. Leung DY, Boyd A, Ng AA, Chi C, Thomas L. Echocardiographic evaluation of left atrial size and function: current understanding, pathophysiologic correlates, and prognostic implications. Am Heart J 2008; 156:1056-64.

31. Appleton CP, Galloway JM, Gonzalez MS, Gaballa M, Basnight MA. Estimation of left ventricular filling pressures using twodimensional and Doppler echocardiography in adult patients with cardiac disease. Additional value of analyzing left atrial size, left atrial ejection fraction and the difference in duration of pulmonary venous and mitral flow velocity at atrial contraction. J Am Coll Cardiol. 1993; 22: 1972-82.

32. Brecht A, Oertelt-Prigione S, Seeland U, Rucke M, Hattasch R, Wagelohner T, et al. Left atrial function in preclinical diastolic dysfunction: two-dimensional speckle-tracking echocardiography - derived results from the BEFRI Trial. J Am Soc Echocardiogr 2016; 29: 750-8.

33. Sargento L, Vicente Simoes A, Longo S, Lousada N, Palma Dos Reis R. Left atrial function index predicts long-term survival in stable outpatients with systolic heart failure. Eur Heart J Cardiovasc Imaging. 2017; 18: 119-27.

34. Saraiva RM, Demirkol S, Buakhamsri A, Greenberg N, Popovic ZB, Thomas JD, et al. Left atrial strain measured by two-dimensional speckle tracking represents a new tool to evaluate left atrial function. J Am Soc Echocardiogr 2010; 23: 172-80.

35. Spencer KT, Mor-Avi V, Gorcsan J, 3rd, DeMaria AN, Kimball TR, Monaghan MJ, et al. Effects of aging on left atrial reservoir, conduit, and booster pump function: a multi-institution acoustic quantification study. Heart 2001; 85: 272-7.

36. Tadic M, Cuspidi C, Pencic B, Rihor B, Radojkovic J, Kocijanic V, et al. The influence of white-coat hypertension on left atrial phasic function. Blood Press 2017; 26: 102-8.

37. Bilen E, Kurt M, Tanboga IH, Kocak U, Ayhan H, Durmaz T, et al. Assessment of left atrial phasic functions in heart failure patients with preserved or low ejection fractions. Arch Turk Soc Cardiol 2012; 40: 122-8.

38. Gupta S, Matulevicius SA, Ayers CR, Berry JD, Patel PC, Markham DW, et al. Left atrial structure and function and clinical outcomes in the general population. Eur Heart J 2013; 34: 278-85.

39. Abhayaratna WP, Fatema K, Barnes ME, Seward JB, Gersh BJ, Bailey KR, et al. Left atrial reservoir function as a potent marker for first atrial fibrillation or flutter in persons $>$ or $=65$ years of age. Am J Cardiol 2008;101: 1626-9. 
40. Thomas L, Hoy M, Byth K, Schiller NB. The left atrial function index: a rhythm independent marker of atrial function. Eur $\mathrm{J}$ Echocardiogr 2008; 9: 356-62.

41. Zhang Q, Yip GW, Yu CM. Approaching regional left atrial function by tissue Doppler velocity and strain imaging. Europace 2008; 10 Suppl 3:iii62-9.

42. Hesse B, Schuele SU, Thamilasaran M, Thomas J, Rodriguez L. A rapid method to quantify left atrial contractile function: Doppler tissue imaging of the mitral annulus during atrial systole. Eur J Echocardiogr. 2004; 5: 86-92.

43. Wang M, Yip GW, Wang AY, Zhang Y, Ho PY, Tse MK, et al. Peak early diastolic mitral annulus velocity by tissue Doppler imaging adds independent and incremental prognostic value. J Am Coll Cardiol 2003; 41: 820-6.

44. Agoston G, Gargani L, Miglioranza MH, Caputo M, Badano LP, Moreo A, et al. Left atrial dysfunction detected by speckle tracking in patients with systemic sclerosis. Cardiovasc Ultrasound 2014;12: 30.

45. Shih JY, Tsai WC, Huang YY, Liu YW, Lin CC, Huang YS, et al. Association of decreased left atrial strain and strain rate with stroke in chronic atrial fibrillation. J Am Soc Echocardiogr 2011; 24: 513-9.

46. Ersboll M, Andersen MJ, Valeur N, Mogensen UM, Waziri H, Moller JE, et al. The prognostic value of left atrial peak reservoir strain in acute myocardial infarction is dependent on left ventricular longitudinal function and left atrial size. Circulation Cardiovasc Imaging 2013; 6: 2633.

47. Cameli M, Lisi M, Giacomin E, Caputo M, Navarri R, Malandrino A, et al. Chronic mitral regurgitation: left atrial deformation analysis by two-dimensional speckle tracking echocardiography.Echocardiography 2011; 28: 327-34.

48. Oakes RS, Badger TJ, Kholmovski EG, Akoum N, Burgon NS, Fish EN, et al. Detection and quantification of left atrial structural remodeling with delayed-enhancement magnetic resonance imaging in patients with atrial fibrillation. Circulation 2009; 119: 1758-67.

49. Her AY, Choi EY, Shim CY, Song BW, Lee S, Ha JW, et al. Prediction of left atrial fibrosis with speckle tracking echocardiography in mitral valve disease: a comparative study with histopathology. Korean Circ J 2012; 42: 311-8.

50. Cameli M, Ciccone MM, Maiello M, Modesti PA, Muiesan ML, Scicchitano P, et al. Speckle tracking analysis: a new tool for left atrial function analysis in systemic hypertension: an overview. J Cardiovasc Med (Hagerstown) 2016; 17: 339-43.

51. Kuppahally SS, Akoum N, Burgon NS, Badger TJ, Kholmovski EG, Vijayakumar S, et al. Left atrial strain and strain rate in patients with paroxysmal and persistent atrial fibrillation: relationship to left atrial structural remodeling detected by delayed-enhancement MRI. Circulation Cardiovasc Imaging 2010; 3: 231-9.

52. Cameli M, Lisi M, Righini FM, Massoni A, Natali BM, Focardi M, et al. Usefulness of atrial deformation analysis to predict left atrial fibrosis and endocardial thickness in patients undergoing mitral valve operations for severe mitral regurgitation secondary to mitral valve prolapse. Am J Cardiol 2013; 111: 595-601.

53. Mor-Avi V, Yodwut C, Jenkins C, Kuhl H, Nesser HJ, Marwick TH, et al. Real-time 3D echocardiographic quantification of left atrial volume: multicenter study for validation with CMR. JACC Cardiovasc Imaging 2012;5:769-77.

54. Miyasaka $\mathrm{Y}$, Tsujimoto $\mathrm{S}$, Maeba $\mathrm{H}$, Yuasa F, Takehana K, Dote K, et al. Left atrial volume by real-time three-dimensional echocardiography: validation by 64-slice multidetector computed tomography. J Am Soc Echocardiogr 2011; 24: 680-6.

55. Aune E, Baekkevar M, Roislien J, Rodevand O, Otterstad JE. Normal reference ranges for left and right atrial volume indexes and ejection fractions obtained with real-time threedimensional echocardiography. Euro J Echocardiogr 2009; 10: 738-44.

56. Cameli, M, Lisi, M, Righini FM, Mondillo S. Novel echocardiographic techniques to assess left atrial size, anatomy and function.

Cardiovasc Ultrasound 2012; 10: 4.

57. Nemes A, Piros GA, Lengyel C, Domsik P, Kalapos A, Varkonyi TT, et al. Complex evaluation of left atrial dysfunction in patients with type 1 diabetes mellitus by three-dimensional speckle tracking echocardiography: results from the MAGYAR-Path Study. Anatol J Cardiol 2016; 16: 587-93. 
58. Gaynor SL, Maniar HS, Prasad SM, Steendijk P, Moon MR. Reservoir and conduit function of right atrium: impact on right ventricular filling and cardiac output. Am J Physiol Heart Circ Physiol 2005; 288: H2140-5.

59. Gaynor SL, Maniar HS, Bloch JB, Steendijk P, Moon MR. Right atrial and ventricular adaptation to chronic right ventricular pressure overload. Circulation. 2005; 112 (9 Suppl): I212-8.

60. Teixeira R, Monteiro R, Garcia J, Baptista R, Ribeiro M, Cardim N, et al. The relationship between tricuspid regurgitation severity and right atrial mechanics: a speckle tracking echocardiography study. Int J Cardiovasc Imaging 2015; 31: 1125-35.

61. Austin C, Alassas K, Burger C, Safford R, Pagan R, Duello K, et al. Echocardiographic assessment of estimated right atrial pressure and size predicts mortality in pulmonary arterial hypertension. Chest 2015; 147: 198-208.

62. Fukuda Y, Tanaka H, Motoji Y, Ryo K, Sawa T, Imanishi J, et al. Utility of combining assessment of right ventricular function and right atrial remodeling as a prognostic factor for patients with pulmonary hypertension. Int $\mathbf{J}$ Cardiovasc Imaging 2014; 30: 1269-77.

63. Sato T, Tsujino I, Ohira H, OyamaManabe N, Ito YM, Yamada A, et al. Right atrial volume and reservoir function are novel independent predictors of clinical worsening in patients with pulmonary hypertension. J Heart Lung Transplant 2015; 34: 414-23.

64. Moceri P, Dimopoulos K, Liodakis E, Germanakis I, Kempny A, Diller GP, et al. Echocardiographic predictors of outcome in eisenmenger syndrome. Circulation 2012; 126: 1461-8.
65. Chow V, Ng AC, Chung T, Thomas L, Kritharides L. Right atrial to left atrial area ratio on early echocardiography predicts long-term survival after acute pulmonary embolism. Cardiovascultrasound 2013; 11: 17.

66. Peluso D, Badano LP, Muraru D, Dal Bianco L, Cucchini U, Kocabay G, et al. Right atrial size and function assessed with threedimensional and speckle-tracking echocardiography in 200 healthy volunteers. Eur Heart J Cardiovasc Imaging 2013; 14: 1106-14.

67. Padeletti M, Cameli M, Lisi M, Malandrino A, Zaca V, Mondillo S. Reference values of right atrial longitudinal strain imaging by two-dimensional speckle tracking. Echocardiography 2012; 29: 147-52.

68. Bhave NM, Visovatti SH, Kulick B, Kolias TJ, McLaughlin VV. Right atrial strain is predictive of clinical outcomes and invasive hemodynamic data in group 1 pulmonary arterial hypertension. Int J Cardiovasc Imaging 2017; 33: 847-55.

69. Moreno J, Perez de Isla L, Campos N, Guinea J, Dominguez-Perez L, Saltijeral A, et al. Right atrial indexed volume in healthy adult population: reference values for two-dimensional and three-dimensional echocardiographic measurements. Echocardiography 2013; 30: 66771. 